\title{
Tracheal gas insufflation: a useful adjunct to ventilation?
}

High transalveolar cycling pressures are often developed in order to bring sufficient fresh gas into contact with the capillary blood to satisfy ventilatory demands or therapeutic targets. An elevated breathing workload, high ventilating pressures, and alveolar overdistension are characteristic of status asthmaticus and acute exacerbations of chronic airflow obstruction. Certain lung units may also experience overinflation during the conventional management of the acute respiratory distress syndrome (ARDS). It is now understood that fewer than one third of all alveoli may remain accessible to gas during acute lung injury, ${ }^{1}$ and that the stretching forces developed in achieving normocapnia with this reduced capacity may cause further damage or retard healing. ${ }^{2-4}$ Such knowledge has inspired various innovative approaches for accomplishing ventilation during critical illness, whose ultimate value remains unproven. Among these the technique of using smaller tidal volumes and "permissive hypercapnia" is perhaps the simplest and most widely applied. ${ }^{5}$ Experience already acquired with this technique suggests that it is tolerated quite well by most patients. ${ }^{6}$ Rapid accumulation of carbon dioxide, however, may produce sufficient intracellular acidosis to interfere with appropriate functioning of the cardiovascular and nervous systems. Moreover, extreme hypercapnia seems inadvisable for patients with intracranial lesions, head trauma, cerebral haemorrhage, or hypertension, and may be difficult or impossible to implement in patients with coexisting metabolic acidosis.

Whether the problem is primarily one of an excessive breathing workload, of alveolar overdistension, or of undesired hypercapnia that develops as a consequence of a lung protective strategy, it would be useful to achieve adequate ventilation levels without the need for high cycling pressures. Extracorporeal carbon dioxide removal or membrane oxygenation and intravena caval gas exchange (IVOX) are expensive and invasive examples of such methods whose success depends largely on patient selection and the skill and experience of the care providers. ${ }^{78}$

Tracheal gas insufflation represents a less invasive option which is potentially applicable to a broad spectrum of clinical problems. ${ }^{9}$ For many years interest has persisted in achieving ventilation without phasic airway pressure by introducing high flows of fresh gas near the main carina in a valveless system. ${ }^{10}$ In fact, constant flow ventilation can maintain an elevated (but stable) level of $\mathrm{PaCO}_{2}$ for several hours in apnoeic dogs when very high flows are delivered through catheters positioned beyond the carina. ${ }^{11}$ Such methods can sustain acceptable arterial oxygenation in humans, but constant flow ventilation does not accomplish adequate carbon dioxide elimination. ${ }^{12}$ Nevertheless, tracheal injection of fresh gas may be an effective adjunct to a system in which cyclic pressures are generated.

Inefficient ventilation often results from driving small tidal volumes through a network of non-gas exchanging conducting airways. As a partial remedy the dead space of the upper airway is bypassed whenever tracheostomy is employed as a treatment for patients with chronic ventilatory failure. Active flushing of the proximal dead space can serve a similar function when tracheostomy is not performed. In 1969 Stresemann et al demonstrated the potential usefulness of actively flushing the proximal anatomical dead space in two patients with obstructive lung disease. ${ }^{13}$
More recently transtracheal systems for long term oxygen delivery have been noted to reduce the minute ventilation associated with a specific $\mathrm{PaCO}_{2}$ and to improve exercise tolerance, ${ }^{1415}$ presumably because transtracheal catheters injecting continuous low flows of oxygen perform a similar (dead space flushing) function.

A considerable body of experimental work in animals, ${ }^{16-21}$ as well as more limited clinical data, ${ }^{22-27}$ indicates the potential value of adjunctive tracheal gas insufflation in an intensive care setting. The efficiency of tracheal gas insufflation relates directly to the prior contribution of the volume proximal to the orifice of the flushing catheter to the total physiological dead space. ${ }^{28}$ Wasted ventilation can be thought of in two ways: firstly, as the volume of fresh gas delivered to unperfused alveolar units and, secondly, as the volume of gas recycled to the alveoli during inspiration with a carbon dioxide concentration identical to that of the pulmonary arterial blood (usually well approximated by $\mathrm{PaCO}_{2}$ ). The proximal dead space can therefore be thought of as the product of the physical volume of the flushable segment of the inspiratory airway and the ratio of the end expiratory carbon dioxide concentration of gas within that segment relative to that of the pulmonary artery or a well perfused alveolus. Disease-induced mismatching of perfusion to ventilation increases the percentage of alveolar dead space and simultaneously decreases the mean alveolar $\mathrm{PCO}_{2}$. Consequently the carbon dioxide concentration of the gas that resides in the central airways at end expiration falls, limiting the change in $\mathrm{PCO}_{2}$ that occurs after it is replaced by catheter-derived fresh gas. On the other hand, small tidal volumes accentuate the contribution of the proximal series dead space to carbon dioxide retention, and hypercapnia helps to raise the expiratory concentration of carbon dioxide within the flushable region before tracheal gas insufflation is initiated. Both hypercapnia and reduced tidal volumes are characteristic of a lung protective strategy for ventilating patients with ARDS and status asthmaticus.

During tracheal gas insufflation-assisted ventilation $\mathrm{PaCO}_{2}$ falls in a direct but non-linear relation to the rate of catheter flow. ${ }^{1929}$ Modest flows of fresh gas achieve nearly maximal benefit, as expected for a washout effect in a confined volume. Although flushing of the dead space proximal to the catheter orifice is undoubtedly the primary mechanism of action for tracheal gas insufflation, a jet of fresh catheter gas projects for a variable distance beyond the catheter orifice itself, extending the flushed region and improving distal gas mixing. This projection may explain why a straight catheter directed toward the main carina performs more effectively than one with an inverted tip whose orifice lies in the same transverse plane within the airway but points (mouthward) in the opposite direction. ${ }^{29}$ Non-bulk flow mechanisms of accomplishing alveolar gas exchange seem less important at the jet velocities achieved with the flows and catheter diameters generally used in experimental studies. Although catheters placed closer to the main carina perform somewhat better than those more proximal, the site of gas injection only moderately affects the efficiency of tracheal gas insufflation-aided ventilation. ${ }^{20}$

How best to coordinate catheter injection with the cycling pattern of the ventilator has not yet been clearly defined. From recent animal experiments it appears that 
pan expiratory injection of catheter gas is equally as effective as continuous tracheal gas insufflation, provided inspiratory tidal volumes are equivalent and identical volumes of fresh gas enter the trachea during the expiratory period. ${ }^{2930}$ Preserving the full ventilatory benefit of tracheal gas insufflation without the need for catheter flow during inspiration may be advantageous. High catheter flows may be required for optimal efficiency during the ventilation of certain patients with ARDS, especially when high ventilating frequencies or extended inspiratory time fractions limit the time available for expiratory flushing. The tracheal gas insufflation catheter effectively functions as a ventilator when the expiratory valve of the circuit is closed. Consequently continuous catheter flows may potentially increase the total inspired tidal volume and thereby lead to hyperinflation and violation of pressurelimiting guidelines unless an appropriate ventilator adjustment is made. (This is especially true during volume cycled ventilation when flows from ventilator and catheter are directly additive.) Catheter flow restricted to expiration, on the other hand, can be provided without risking end inspiratory overdistension or the need to restrict the flow range, provided that pressure controlled ventilation is used, or tidal volume is adjusted for any resulting autoPEEP. Another advantage of using selective expiratory tracheal gas insufflation is that, unlike continuous tracheal gas insufflation, expiratory tracheal gas insufflation allows static conditions to be established during interruption of inspiratory flow. The pressure recorded during an end inspiratory pause therefore continues to reflect the average end inspiratory alveolar ("plateau") pressure (the sum of PEEP, auto-PEEP, and the quotient of tidal volume and respiratory system compliance).

Any "auto-PEEP" caused by tracheal gas insufflation may present either a problem or a therapeutic option. Even a phasic expiratory jet may raise mean alveolar pressure by directly opposing lung deflation, as well as by generating a back pressure across the endotracheal tube and expiration valve. Both effects are functions of catheter flow rate. Reducing the resistance of the endotracheal tube and expiratory valve are, therefore, the key to limiting the pressure which opposes lung deflation.

Because tracheal gas insufflation tends to raise end expiratory and mean alveolar pressures, it may improve arterial oxygenation in patients with parenchymal lung injury. An increase in mean alveolar pressure occurs routinely when continuous tracheal gas insufflation is added to an unchanging tidal volume delivered by the ventilator. Augmentation of end expiratory lung volume and mean alveolar pressure also occur, however, during selective expiratory injection. Such a mechanism may improve oxygenation in patients with acute lung injury.

Certain safety issues must be resolved before tracheal gas insufflation can be accepted for routine clinical use. Important questions relate to the need to humidify catheter gas and to address the purely technical problem of providing a pressure relief mechanism to stop catheter flow in the event of sudden endotracheal tube occlusion. Furthermore, it is uncertain whether tracheal damage might result from an intense or prolonged catheter jet even one restricted to the expiratory phase. Finally, an intraluminal catheter interferes with expiratory flow and with the elimination of airway secretions. The possibilities of extraluminal catheter placement or of injecting gas through channels embedded in the walls of an endotracheal tube specially constructed for this purpose are therefore especially interesting.

Although some work has been done in chronically ill patients with diseased airways, ${ }^{13-152627}$ the application of tracheal gas insufflation to critically ill patients with severe airflow obstruction has been very limited. Its effects may well vary with the type of obstruction under treatment. As already noted, the existence of a high alveolar dead space fraction tends to limit the effectiveness of tracheal gas insufflation, while hypercapnia tends to improve it. Therefore, for the patient with chronic bronchitis whose lung parenchyma is relatively normal, whose airways are intrinsically obstructed, and who retains carbon dioxide, tracheal gas insufflation would appear to be a particularly attractive option. For patients with emphysema, whose abnormal parenchyma produces high alveolar dead space and whose airways are functionally compressed, the benefit is less clear.

Other effects of tracheal gas insufflation on dyspnoea and the work of breathing have yet to be explored, especially in patients with airflow obstruction. Dynamic hyperinflation resulting from the flow retarding effects of tracheal gas insufflation could conceivably interfere with ventilator triggering or cause functional weakening of the inspiratory musculature. Alternatively, in the setting of tidal flow limitation, the flow retarding effects of tracheal gas insufflation could prove inconsequential. It is even possible that dilatation of airways downstream from the site of flow limitation might improve the sensation of dyspnoea. ${ }^{31}$

Patients who have neuromuscular weakness as the primary cause of ventilatory failure are good candidates to benefit from tracheal gas insufflation. In these patients small tidal volumes, carbon dioxide retention, and dyspnoea typically result from a disproportion between workload and work capacity. The lung parenchyma often remains relatively normal. Conceptually, at least, the relatively large contribution of the proximal airway to the total physiological dead space fraction should boost the effectiveness of tracheal gas insufflation. Improved carbon dioxide elimination without the need to increase ventilation pressure allows the spontaneously breathing patient to reduce $\mathrm{PaCO}_{2}$, limit total ventilatory effort, or both.

Tracheal gas insufflation has clear potential to improve the management of acute lung injury by reducing pressure requirements or by constraining the level of hypercapnia or the pace of its development. It is also a promising technique for certain forms of airflow obstruction and neuromuscular weakness, and could also conceivably facilitate ventilator weaning. Yet until the questions regarding its safety and efficacy are resolved and its operational characteristics are better defined, the clinical use of tracheal gas insufflation should be considered experimental.

Professor of Medicine,

University of Minnesota

Minneapolis/St Paul,

Minnesota 55101-2595, USA

JOHN J MARINI

Gattinoni L, Pesenti A, Bombino M. Relationships between lung computed tomographic density, gas exchange, and PEEP in acute respiratory failure. Anesthesiology 1988;69:824-32

2 Webb HH, Tierney DF. Experimental pulmonary edema due to intermittent positive pressure ventilation with high inflation pressures. Protection by positive end-expiratory pressure. Am Rev Respir Dis 1974;110:556-65.

3 Dreyfuss D, Soler P, Basset G, Saumon G. High inflation pressure pulmonary edema. Respective effects of high airway pressure, high tida volume, and positive end expiratory pressure. Am Rev Respir Dis 1988;137:1159-64

4 Kolobow T, Moretti MP, Fumagalli R, Mascheroni D, Prato P, Chen V, et al. Severe impairment of lung function induced by high peak airway pressure during mechanical ventilation. Am Rev Respir Dis 1987;135: 312-5.

5 Hickling KG, Henderson SJ, Jackson R. Low mortality associated with low volume, pressure limited ventilation with permissive hypercapnia in , Permissive hypercapnia Respir Care 1993;38:373-87.

7 Gattinoni L. Brazzi L. Pesenti A. Extracorporeal carbon dioxide removal in ARDS. In: Marini JJ, Roussos C, eds. Ventilatory failure. Berlin: Springer-Verlag, 1991:308-17. 
8 Mortensen JD. Augmentation of blood gas transfer by means of an intravascular blood gas exchanger (IVOX). In: Marini JJ, Roussos C, eds. Ventilatory failure. Berlin: Springer-Verlag, 1991:318-46.

9 Nahum A, Marini JJ. Tracheal gas insufflation as an adjunct to conventional ventilation. In: Vincent JL, ed. Yearbook of intensive care and emergency medicine. Berlin: Springer-Verlag, 1994:511-23.

10 Meltzer SJ, Auer J. Continuous respiration without respiratory movements. F Exp Med 1909;11:622-5.

11 Slutsky AS, Watson J, Leith DE, Brown R. Tracheal insufflation of $\mathrm{O}_{2}$ (TRIO) at low flow rates sustains life for several hours. Anesthesiology 1985;63:278-86.

12 Breen PH, Sznajder JI, Morrison P, Hatch D, Wood LDH, Craig DB. Constant flow ventilation in anesthetized patients: safety and efficacy. Anesth Analg 1986;65:1161-9.

13 Stresemann E, Votteri BA, Sattler FP. Washout of anatomical dead space for alveolar hypoventilation. Respiration 1969;26:425-34

14 Couser JI, Make BJ. Transtracheal oxygen decreases inspired minute ventilation. Am Rev Respir Dis 1989;139:627-31.

15 Benditt J, Pollock M, Roa J, Celli B. Transtracheal delivery of gas decreases the oxygen cost of breathing. Am Rev Respir Dis 1993;147:1207-10.

16 Sznajder JI, Becker CJ, Crawford GP, Wood LDH. Combination of constant-flow and continuous positive-pressure ventilation in canine pulmonary edema. $f$ Appl Physiol 1989;67:817-23.

17 Muller E, Kolobow T, Mandava S, Jones M, Vitale G, Aprigliano M, et al On how to ventilate lungs as small as $12 \%$ of normal. Intratracheal pulmonary ventilation (ITPV). A new mode of pulmonary ventilation. Am Rev Respir Dis 1991;143:A693.

18 Nahum A, Burke WC, Ravenscraft SA, Marcy TW, Adams AB, Crooke PS et al. Lung mechanics and gas exchange during pressure controlled ventilation in dogs: augmentation of $\mathrm{CO}_{\text {, elimination by an intratracheal }}$ catheter. Am Rev Respir Dis 1992;146:965-73.

19 Burke WC, Nahum A, Ravenscraft SA, Nakos G, Adams AB, Marcy TW et al. Modes of tracheal gas insufflation: comparison of continuous and
phase specific gas injection in normal dogs. Am Rev Respir Dis phase specific

20 Nahum A, Ravenscraft SA, Nakos G, Burke WC, Adams AB, Marcy TW, et al. Tracheal gas insufflation during pressure controlled ventilation: effect of catheter position, diameter, and flow rate. Am Rev Respir Dis 1992:146:1411-8.

21 Long SE, Menon AS, Kato H, Goldstein RS, Slutsky AS. Constant oxygen insufflation (COI) in a ventilatory failure model. Am Rev Respir Dis 1988;138:630-5.

22 Ravenscraft SA, Burke WC, Nahum A, Adams AB, Nakos G, Marcy TW, et al. Tracheal gas insufflation augments $\mathrm{CO}_{2}$ clearance during mechanical ventilation. Am Rev Respir Dis 1993;148:345-51.

23 Gilbert J, Larsson A, Smith RB, Bunegin L. Intermittent-flow expiratory ventilation (IFEV): delivery technique and principles of action - a preliminary communication. Biomed Instr Technol 1991;25:451-6.

24 Jonson B, Similowski T, Levy P, Vires N, Pariente R. Expiratory flushing of airways: a method to reduce dead space ventilation. Eur Respir $\mathcal{F}$ 1990;3:1202-5.

25 Wolff G, Brunner JX, Troillet JL. Disturbances of gas exchange in adult respiratory distress syndrome. Atemw Lungenkrkb 1987;13:236-43.

26 Hurewitz A, Bergofsky E, Vomero E. Airway insufflation: increasing flow rates progressively reduce dead space in respiratory failure. Am Rev Respir Dis 1991;144:1229-33.

27 Bergofsky EH, Hurewitz AN. Airway insufflation: physiologic effects on acute and chronic gas exchange in humans. Am Rev Respir Dis 1989;140:885-90.

28 Nahum A, Chandra A, Niknam J, Ravenscraft SA, Adams AB, Marini JJ. Effect of tracheal gas insufflation on gas exchange in canine oleic acid induced lung injury. Crit Care Med 1994 (in press).

29 Nahum A. Ravenscraft SA, Nakos G, Adams AB, Burke WC, Marini JJ. Effect of catheter flow direction on $\mathrm{CO}_{2}$ removal during tracheal gas insufflation. F Appl Physiol 1993;75:1238-46.

30 Ravenscraft SA, Nahum A, Burke WC, Adams AB, Nakos G, Marini JJ. Tracheal gas insufflation (TGI): catheter effectiveness is determined by expiratory flush volume. Am Rev Respir Dis 1992;147:A892.

31 O'Donnell DE, Sanii R, Anthonisen NR, Younes M. Effect of dynamic airway compression on breathing pattern and respiratory sensation in severe chronic obstructive pulmonary disease. Am Rev Respir Dis 1987;135:912-8. 